\title{
The Sociolinguistic Dimensions of Code-Switching between Arabic and English by Saudis
}

\author{
Manal A. Ismail ${ }^{1}$ \\ ${ }^{1}$ Department of English Language and Literature, King Saud University, Riyadh, Saudi Arabia \\ Correspondence: Manal A. Ismail, Department of English Language and Literature, King Saud University, \\ Riyadh, Saudi Arabia. E-mail: maismail@ksu.edu.sa
}

\author{
Received: August 10, 2015 Accepted: September 1, 2015 Online Published: September 29, 2015 \\ doi:10.5539/ijel.v5n5p99 URL: http://dx.doi.org/10.5539/ijel.v5n5p99
}

\begin{abstract}
The neglected area of Arab speakers' verbal performance in mixed-sex contexts is the focus of this study. This paper attempts to contribute to this area by studying the frequency and type of code-switches from Arabic into English in the casual conversations of young bilingual Saudis. Findings indicate that Saudi females' style of speech was characterized by substantially more code-switching from Arabic into English particularly single noun and adjective switches than their male counterparts in both single and mixed sex interactions. Women's turn-switches were marked by more linguistic convergence between one another, however they were less inclined to turn-switch to the language of a speaker of the opposite sex. Men's code-switching performance at a turn boundary was overall more inclined towards linguistic divergence. The findings in relation to turn-switching would indicate that although these women and men interacted in mixed-sex settings, they still seemed to adhere to Saudi cultural values that encourage social distance between the sexes. It is argued that underpinning Arab women's and men's code-switching behavior are lingering cultural customs and gendered ideologies of language.
\end{abstract}

Keywords: Saudi Arabia, Arabic, English, code-switching, gender, culture

\section{Introduction}

Both the area of language and gender and the phenomena of code-switching (hereafter CS) in bilingual speech have experienced a great deal of scientific interest. Despite the focus of interest in these areas of linguistic enquiry, researchers have paid little attention to examining the intersection of CS with gender. Even though CS patterns may be a convenient linguistic tool for examining norms of verbal behavior by women and men, especially in mixed-sex contexts where gender roles are continuously constructed and redefined by speakers.

Significantly, the area of language and gender in Arabic speech communities remains a relatively unexplored area. Much of the research that has examined Arab women's and men's speech has generally focused on single-sex interactions because many Arab cultures discourage mingling of the sexes outside the context of family. This is particularly the case in Saudi Arabia, a conservative Moslem Arab society where social and physical segregation of the sexes is common. A younger generation of Saudis are nonetheless breaking away from traditional views of gender segregation in response to a rapidly changing social, economic, and cultural transformation of the country and are choosing to interact in mixed-sex contexts. Settings where Arab women and men are free to interact with one another are a fruitful site of linguistic investigation. As such, the present study seeks to examine the CS performance of young Saudi couples during mixed-sex dinner gatherings. Specifically, the frequency and type of CS from Arabic into English are counted in each sexes' speech. To my knowledge, no quantitative study has been published on Arabic-English CS by Saudis in mixed-sex contexts using recorded natural data. The aim is to fill-in the gap in the literature on Saudi's verbal behavior in mixed-sex contexts and to contribute to the areas of CS and language and gender in general.

The paper is organized as follows. CS is first defined and then an overview of the relevant literature on CS is provided. Studies that examine the intersection of CS and gender are surveyed in various communities with a focus on Arabic speech communities. The methodology is then outlined and significant demographic data regarding the participants in this study are provided. What to include as CS is addressed, as well as coding of CS data is discussed in relation to the corpus. A quantitative description of CS types is provided for each gender in the context of single-sex and mixed-sex interactions. Finally, a few tentative generalizations are offered in 
relation to Saudi women's and men's CS performance.

\section{Defining CS}

It is common for bilinguals to alternate between two languages in the same conversation. The term CS is usually used to describe this linguistic behavior. The literature is however awash with a range of terms describing different aspects of this verbal behavior, for example, code-mixing, code-borrowing, insertion, alternation, and congruent lexicalization. Definitions are problematic and an area of contention by scholars in the field primarily because the linguistic criteria used to differentiate between CS terms often overlap (see, e.g., Auer, 1998; Gardner-Chloros, 2009; Muysken, 2000; Myers-Scotton, 1992; Romaine, 1995). This paper adopts Auer's (1998, p. 1) definition of CS, that is "the 'alternating use of two or more "codes" within one conversational episode' (thus the usual definition)" (Note 1). This working definition places emphasis on CS as a conversational event. The adoption of such a broad definition that places emphasis on the social is relevant to the present study, which seeks to examine CS in speakers' casual conversations.

There are many types of switches that can occur in the same discourse. In general, there are two points where CS can occur: intersententially and intrasententially. The former can occur across sentences, clause boundaries or between speaker turns, whereas the latter occurs within a sentence, clause or word boundary (Romaine, 1995, pp. 122-123). Cheshire and Gardner-Chloros (1998) in their classification of CS types additionally made a distinction between intrasentential switching and the most common type of switching, single-word switches. They also categorized turn-switching as a separate category from intersentential switching. Turn-switching was defined as a change in the bilingual's language from the previous speaker and an indicator of uncooperative communication (Cheshire \& Gardner-Chloros, 1998, p. 20). In contrast, Valdès-Fallis (1978 cited in Cheshire \& Gardner-Chloros, 1998, p. 16) used the term "sequential switches" to characterize a switch into the preceding speaker's language and viewed this type of switch as an index of the speaker's cooperativeness in the conversation. It is significant to point out that classifying switches at a turn boundary as either a switch away or towards the previous speaker's/ interlocutor's language delimits the data because each switch eliminates the other in the categorization of this type of CS.

\section{An Overview of CS}

In order to analyze CS utterances, there is a need to differentiate between base and embedded language. This distinction forms the basis of one of the most influential production based models in the CS literature, the Matrix Language Frame Model (MLF Model) by Myers-Scotton (1993). In the MLF Model, there is a hierarchical interplay between the bilingual's languages, in other words one of the languages involved in CS plays a dominant role. The dominant language in the bilingual's performance is the base or Matrix Language (ML) and the other language, the Embedded Language (EL), plays a lesser role. The major argument of the model is that the grammar of the ML sets the morphosyntactic frame of intrasentential EL constituents that participate in CS. The ML supplies content constituents and system morphemes to the CS utterance, while the EL supplies only content morphemes. During extended discourse, the ML would contribute the greater number of morphemes and forms the larger part of the corpus. However, both the morphosyntactic and quantitative based measures to determine the ML have been shown not to be applicable to some examples of CS data, for instance, Kebeya (2013) CS data in Kenya. Psycholinguistic and social factors that have additionally been provided to identify the ML are problematic as well. The assumption that the speaker has better competence in the ML is often not true, a bilingual may have similar competence in both languages or more competence in the EL. Although, social factors may determine the ML as the unmarked (or expected) choice for a domain or interaction type, there are many other factors that motivate CS such as discourse related functions (e.g., Alfonzetti, 1998). Thus, determining the ML is not always easy and for this reason there is a need to consider the applicability of as many criteria as possible.

Some of the insights from CS research in various communities and the gathering of different types of data merit particular attention. It has long been recognized that a variety of context dependent factors influence the bilingual's choice of language. For example, Finnis (2014) found the number of code-switches for Greek-Cypriots to be more during their monthly youth organization meetings than during a dinner gathering. Some studies have indicated that certain types of switching require greater fluency/proficiency in both languages. Let us briefly offer Poplack's (1980, p. 589) finding that points to a strong relation between bilingual proficiency and greater tendency for intrasentential switching presumably because the switched segment needs to conform to the underlying syntactic rules of both languages. Alternatively, Myers-Scotton (1993, p. 71) believes that intersentential CS is the more skilled CS because it requires the speaker to have command in both languages in order to produce utterances that conform to the grammatical rules of either language. It is significant to point out 
that the correlation between competence and types of CS is disputed (see, e.g., Gardner-Chloros, 2009; Romaine, 1995). There is, on the other hand, a substantial amount of data that shows that within the category of intrasentential switching there exists a hierarchy of frequently switched constituents. In general, nouns and compound nouns are the most frequently switched categories (Appel \& Muysken, 1987; Gardner-Chloros, 2009; Muysken, 2000; Myers-Scotton, 1993, 2002; Poplack, 1980; Romaine, 1995). It is also widely accepted that CS is not random. Grammatical constraints on where CS can occur within an utterance have been proposed e.g. Equivalence and Free Morpheme constraints (Poplack, 1980) and Blocking Hypothesis (Myers-Scotton, 1993). Some CS patterns can be explained by typological differences between languages e.g., agglutination (Muysken, 2000). Thus, a variety of social and psycholinguistic factors may influence the bilingual's choice of language.

\section{CS and Gender}

Gender, an important sociolinguistic variable, has been given less prominence in the CS literature. In the diverse communities were the link between gender and CS has been explored the results are varied. Some studies have found differences in the quantity and type of CS used by each gender within the same community. For example, Poplack's (1980) study of Puerto Rican speakers of Spanish and English in New York found type of CS to be highly correlated with gender, specifically over half of the intrasentential switches were produced by women, whilst men produced about a third of this type. Other studies, on the other hand, show no direct correlation between gender and CS. Such as Cheshire's and Gardner-Chloros's (1998) study which examined two immigrant communities in Britain, the Greek-Cypriot and Punjabi community, and found no significant differences between women and men in both communities regarding their overall rate and type of switching. Finnis (2014) however provides data regarding the London based Greek-Cypriot community that indicate that women and men may code-switch for different reasons. That is, men code-switched more than women into the Greek-Cypriot dialect while telling jokes to establish and maintain rapport, whilst women's CS was often used to express reproach and directness. These differing findings point to the need to explore further the link between CS and gender across different cultures.

Arab speaking communities provide a fertile site for examining CS. A younger generation of Arabs are preferring to use more English borrowed words and expressions in their style of speech in order to be distinctive from older generations (Hassanein, 2009, p. 766). In some Arab communities, gender seems to play a significant role in Arabs' CS performance. Sadiqi (2003, p. 158) observed Moroccan women during mixed-sex conversations to switch their speech between Moroccan Arabic and French more than men so as to gain social prestige and "to 'fight' for self-assertion". Formal studies carried out in Hebron and Jordan found significant gender differences in the use of English borrowed words or loans that were elicited from university students using questionnaires (Atawneh, 2007; Al Batoush, 2014). Significantly, Arabic females preferred to use more English loanwords than their male counterparts. Atawneh's study (2007, p. 33) found women used double the number of loanwords than their male counterparts mostly in the semantic domain of "health, body, foods", whilst men used more loanwords related to the "car industry", this difference was perceived to reflect the different concerns of each gender. However, there was no difference detected in Arab women's and men's usage of loanwords related to the "computer industry" because computers have become an integral part of a modern lifestyle (Atawneh, 2007, p. 34). Drawing on semi-directed linguistic interviews, Sayahi (2011) found gender was not a significant determining factor in frequency or patterns of CS from Arabic into English by Tunisians, whereas education was an important factor. That is, university educated Tunisians code-switched and borrowed more French items than high-school educated Tunisians. Note that Atawneh's (2007) and Al Batoush's (2014) findings were mainly based on data elicited from questionnaires and Sayahi's (2011) study used recorded verbal data from interviews, however CS is a social phenomena that should be ideally studied in naturally occurring settings. The present study aims to explore CS in natural contexts by examining the casual conversations of bilingual Saudi women and men in mixed-sex settings.

\section{Methodology}

\subsection{Data Collection}

The data drew on the speech of six married Saudi couples that often met in each other's homes for dinner. It is significant to mention that the women and men are friends and frequently socialized in contexts other than these encounters. The speech of participants was recorded during two dinner gatherings. Each recording varied in length, the first was about 42 minutes and the other was nearly 47 minutes, making a total of approximately 89 minutes of recorded data. Subjects were informed that they would be recorded specifically for research purposes. The data was collected in the home of one of the female participants in the study to ensure that the context was kept relatively constant. The researcher transcribed the data and determined the type and frequency of English 
CS used by each gender.

\subsection{Demographic Characteristics of Participants}

The age range of the participants was between twenty-eight and thirty-seven. Subjects' mother tongue is Arabic, but were instructed in English at private universities in the Kingdom of Saudi Arabia and in universities in England and America and were able to communicate intelligibly in both Arabic and English. Accordingly, participants can be described as communicative Arabic-English bilinguals. All were university graduates. Two of the women were homemakers, one was a pre-school teacher, one worked in a bank, another in her father's business, and one of the women had her own interior design business. The men held employment positions in diverse fields. Two of the men worked in various financial institutions, another in an insurance corporation, one in a pharmaceutical company, whilst two held positions in their family run companies.

\subsection{What Constitutes CS Material?}

For the data presented here, the ML is Arabic and the EL is English. This differentiation was based on the following two main observations. First, Arabic set the mophosyntacitic frame of English forms, for example, the CS item dailəkt-ein: 'two dialects' had the attached Arabic dual marker -ein suffixed to the English noun 'dialect'. Second, many of the speakers' utterances were in Arabic and did not exhibit CS, which would indicate that Arabic was the unmarked choice in these participants' casual ingroup interactions.

A major issue within the CS literature is which material to include as CS. This issue must be resolved first before any attempt at counting CS data is undertaken. The position taken here is that CS may include any EL material from a single word to several constituents. This can consist of core EL forms "for which the ML has viable equivalents" (Myers-Scotton, 1993, p. 169), for example in our CS corpus the word 'dessert' was used instead of the Arabic ћala: On the other hand, English lexemes that have become part of the community repertoire or what are generally referred to as borrowed or loanwords were not considered part of CS material. For instance, high frequency terms associated with social media technologies such as the lexical items 'post/ repost', 'blog' and 'follow/unfollow'. Similarly, the names of popular social media networks like 'Instagram', 'Snapchat' and 'Facebook'. Terms used for gadgets that have become an integral part of our lives e.g., 'mobile' and 'computer' and their associated applications e.g., 'email', 'CD', software, and 'app'. In addition, English culture-specific items such as proper names, titles of movies, product names, place names, and names of food and drinks.

Both CS items and borrowed English lexemes may be morphosyntactically and phonologically adapted to the grammatical system of Arabic. This was the case for borrowed English forms that were not considered CS material such as the morphologically adapted pluralized form of 'like', laik-a:t, used in reference to social media posts with the attached plural feminine Arabic suffix -a:t, which is commonly used to pluralize English lexical items (Rouchdy, 1992, p. 41), and the regular replacement of [v] with [f] as in fi:zə instead of 'viza'. Similarly, the ML may set the morphosyntactic frame for CS items like ru:m-ik 'your room' with the suffixed Arabic second person singular feminine possessive pronoun $-i k$ to the English lexical item 'room' and saizə-ha: 'her size' with the suffixed third person singular feminine possessive pronoun $-h a$ : to the word 'size'. These observations are in accordance with Myers-Scotton (1993) findings that both CS items and borrowed forms may undergo morphosyntactic integration into the ML.

\subsection{Coding the CS Data}

Four major categories of switching were identified from the transcribed data to be significant in women's and men's CS performance: turn-switching, intersentential switching, intrasentential switching and single-word intrasentential switches. Each type of CS is exemplified and explained in relation to the data presented here. CS items are in bold.

\subsubsection{Turn-Switching}

This is a switch from one language to another at a turn boundary. Two types of turn-switching were identified from the data: sequential and non-sequential. Example 1 illustrates sequential switches in our data, a switch into English at a turn boundary so that the speaker's language corresponds to the interlocutor/previous speaker's language. In contrast, the term non-sequential switching is adopted here to describe a switch into English at a turn boundary even though the interlocutor/previous speaker's language is Arabic as example 2 shows.

(1) A: How was your weekend?

\begin{tabular}{|c|c|c|c|}
\hline B: It was not bad & bi-l-rәьм dzalas- $t$ & $m u § \delta^{\varsigma_{2}}$ & ol-waqt \\
\hline
\end{tabular}

'It was not bad even though I sat most of the time at home.' 
(2) A: $m a:$ fuf-ti wif $s^{5} a: r$

NEG see-you.F. what happened

You didn't see what happened?

B: No. What happened? Yasa: mu: far

No. What happened? Hope NEG evil

'No. What happened? Hope nothing bad.'

The subdivision of turn-switching into sequential and non-sequential CS was seen as necessary in order to take into account both switches at a turn boundary, those that corresponded to the previous speaker's/interlocutor's language and switches that did not. As mentioned previously (refer to section 2 on our criticism of Cheshire and Gardner-Chloros (1998) study), any categorization that does not take into account both types of switches at a turn boundary is incomplete.

\subsubsection{Intersentential Switching}

Intersentential switching is defined here as a switch from one code to another that takes place at a sentence boundary or clause boundary, but not at a turn boundary because this type of CS was treated separately under the category turn-switching (see section 5.4.1). Example 3 is considered an instance of intersentential switching since the speaker switched from an Arabic sentence to an English one in the same turn while complaining that the return trip from America was tiring because of weather conditions, which resulted in approximately one day's delay in flights.
(3) razsat-i:
min Pəmri:kah ka:nat marrah
mut Sibah \| The weather conditions
return-my
from America was very
tiring

\section{delayed flights for like almost twenty-four hours.}

'My return from America was very tiring. The weather conditions delayed flights for like almost twenty-four hours.'

\subsubsection{Intrasentential Switching}

According to our classification system, this type of switching is defined as a switch within a sentence boundary or clause boundary, but does not include single-word switches. Single-word switches are dealt with separately in this paper (see section 5.4.4). Example 4 illustrates an intrasentential switch from the corpus whereby the speaker switches within the Arabic utterence to the English noun phrase 'one month'.

(4) qadam-t Sala: one month iza:zah fi s'eif wo nfa: allah jagbol-u:n-ha:

submit-I on one month vacation in summer and willing God accepts-they-it.F.

'I applied for a one month vacation in summer and God willing they will accept it.'

\subsubsection{Single-Word Intrasentential Switching}

This type of switching involves a single-word switch that may be phonologically and morphosyntactically adapted to the host grammatical system. A preliminary analysis of the CS data on single-word switches appeared to show gender differences in the use of particular parts of speech. As such, single-word switches were further sub-divided according to their grammatical function and four major categories were identified from the data: Nouns, verbs, adjectives and adverbs. Single-word switches consisting of function words were not detected in this corpus. It is however significant to mention that it is possible for function words to be switched intrasententially when two languages share the same grammatical structure as the CS sentence (Muysken, 2000). Examples 5 to 8 show single-word intrasentential switching in the corpus. In example 5 , the speaker utilizes the English noun 'something'. Example 6 illustrates the utilization of the morphosyntactically adapted English verb 'cancel' as kansəl-at-ha: 'cancelled it' with two attached Arabic suffixes: the singular feminine marker -at and third person singular feminine object pronoun $-h a$ : However, example 7 illustrates the speaker utilizing the unmodified English adjective 'objective'. Example 8 shows the speaker resorting to the adverb 'almost' to modify the Arabic lexical item xallas ${ }^{\text {Sat }}$ 'finished'. It is significant to point out that these speakers could have used in examples 5 to 8 the Arabic equivalents such as faj , la satha:, $\operatorname{mawd}\{$ : $\{$ i, and taqri:ban respectivley.
(5) law
Pahtaz- $t$
something balibn-i:
If needed-you.M.
something inform-me

'If you need something let me know.' 


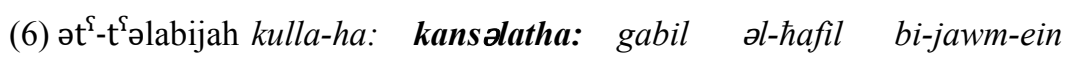
the-order all-it.F. kansolatha: before the-party by-days-two

'All the order kansolatha: two days before the-party.'

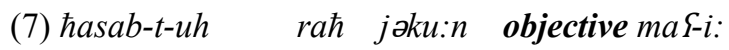

Thought-I-him will be objective with-me.

'I thought that he will be objective with me.'

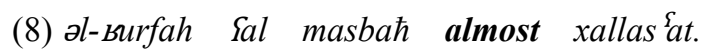

The-room on pool almost finished

'The room on the pool is almost finished.'

\section{Analysis of Data}

\subsection{Overall CS}

The recorded conversations provided a total of 756 instances of CS. Since individuals engage in CS to different extents, the number of code-switches for each of the six female (F1 to F6) and the six male speakers (M1 to M6) were counted and displayed in Table 1.

Table 1. Number of CS occurrences for each subject by gender

\begin{tabular}{lcccccc}
\hline Gender & \multicolumn{5}{c}{ Number of CS Occurrences for Each Subject } \\
\hline Females & F1 & F2 & F3 & F4 & F5 & F6 \\
& 87 & 52 & 68 & 104 & 91 & 84 \\
\hline Males & M1 & M2 & M3 & M4 & M5 & M6 \\
& 36 & 51 & 49 & 44 & 27 & 63 \\
\hline
\end{tabular}

Table 1 shows that all speakers incorporated CS in their speech at some point in their interactions and there seem to be no major outliers, which might have skewed the results of the data. An independent sample t-test showed that women significantly $(\mathrm{p} \leq 0.05$ one-tailed) code-switched into English more than men $(\mathrm{t}=3.971, \mathrm{df}=10, \mathrm{p}=$ $0.003)$.

From the transcribed data, the researcher not only counted the number of times women and men switched from Arabic into English, but also determined whether the switch was a turn-switch, intersentential switch, intrasentential switch, or single-word switch. Turn-switches were subdivided into sequential and non-sequential switches and single-word switches were categorized according to their part of speech (noun [N], verb [V], adjective $[\mathrm{Aj}]$, and adverb $[\mathrm{Av}])$. Table 2 shows the number of occurrences of each CS type in the speech of women and men.

Table 2. Number of CS Occurrences by Type and Gender

\begin{tabular}{|c|c|c|c|c|c|c|c|c|c|}
\hline \multirow[t]{2}{*}{ Gender } & \multicolumn{2}{|c|}{ Turn-Switches } & \multirow[t]{2}{*}{$\begin{array}{c}\text { Intersentential } \\
\text { Switches }\end{array}$} & \multirow[t]{2}{*}{$\begin{array}{c}\text { Intrasentential } \\
\text { Switches }\end{array}$} & \multicolumn{4}{|c|}{$\begin{array}{l}\text { Single-Word } \\
\text { Switches }\end{array}$} & \multirow[t]{2}{*}{ Total } \\
\hline & Sequential & Non-Sequential & & & $\mathrm{N}$ & $\mathrm{V}$ & $\mathrm{Aj}$ & $\mathrm{Av}$ & \\
\hline Females & 56 & 37 & 68 & 59 & 174 & 18 & 72 & 2 & 486 \\
\hline Males & 18 & 44 & 79 & 45 & 69 & 4 & 10 & 1 & 270 \\
\hline Total & 74 & 81 & 147 & 104 & 243 & 22 & 82 & 3 & 756 \\
\hline
\end{tabular}

\subsection{Comparing Single and Mixed-Sex Interactions for Type of CS}

It was important to examine whether CS performance is a function of having an interlocutor of the same sex or opposite sex. Tables 3 and 4 display each CS type as a percentage of total number of switches by both women and men ( 756 switches) to the nearest $0.1 \%$. Table 3 shows the proportion of CS types in each gender's speech during single-sex interactions and table 4 in mixed-sex interactions when the utterances were directed to an interlocutor of the opposite sex or the general audience. The data presented shows that nearly two-thirds of CS was between single-sex conversations (64\%) and about a third during mixed-sex conversations (36\%). This was probably due to the fact that although participants broke away from cultural norms of gender segregation and 
socialized in mixed-sex environments, women and men still preferred to group next to each other and maintain a physical distance between them in the same space. Women chatted more frequently with each other and similarly men with one another and for this reason CS was substantially more in single-sex conversations.

Table 3. Percentage CS Occurrences in Single-sex Interactions by Gender

\begin{tabular}{|c|c|c|c|c|c|c|c|c|c|}
\hline \multirow[t]{2}{*}{ Gender } & \multicolumn{2}{|c|}{ Turn-Switches } & \multirow[t]{2}{*}{$\begin{array}{c}\text { Intersentential } \\
\text { Switches }\end{array}$} & \multirow[t]{2}{*}{$\begin{array}{c}\text { Intrasentential } \\
\text { Switches }\end{array}$} & \multicolumn{4}{|c|}{$\begin{array}{c}\text { Single-Word } \\
\text { Switches } \\
\end{array}$} & \multirow[t]{2}{*}{ Total } \\
\hline & Sequential & Non-Sequential & & & $\mathrm{N}$ & $\mathrm{V}$ & $\mathrm{Aj}$ & $\mathrm{Av}$ & \\
\hline Females & 6.7 & 2.6 & 5.7 & 4.9 & 14.4 & 1.5 & 6.1 & 0.3 & 42.2 \\
\hline Males & 1.6 & 4.1 & 6.1 & 3.2 & 6 & 0.3 & 0.8 & 0 & 22.1 \\
\hline Total & 8.3 & 6.7 & 11.8 & 8.1 & 20.4 & 1.8 & 6.9 & 0.3 & 64.3 \\
\hline
\end{tabular}

Table 4. Percentage CS Occurrences in Mixed-sex Interactions by Gender

\begin{tabular}{|c|c|c|c|c|c|c|c|c|c|}
\hline \multirow[t]{2}{*}{ Gender } & \multicolumn{2}{|c|}{ Turn-Switches } & \multirow[t]{2}{*}{$\begin{array}{c}\text { Intersentential } \\
\text { Switches }\end{array}$} & \multirow[t]{2}{*}{$\begin{array}{c}\text { Intrasentential } \\
\text { Switches }\end{array}$} & \multicolumn{4}{|c|}{$\begin{array}{l}\text { Single-Word } \\
\text { Switches }\end{array}$} & \multirow[t]{2}{*}{ Total } \\
\hline & Sequential & Non-Sequential & & & $\mathrm{N}$ & $\mathrm{V}$ & $\mathrm{Aj}$ & $\mathrm{Av}$ & \\
\hline Females & 0.7 & 2.2 & 3.3 & 2.9 & 8.6 & 0.9 & 3.4 & 0 & 22 \\
\hline Males & 0.8 & 1.7 & 4.4 & 2.8 & 3.2 & 0.3 & 0.5 & 0.1 & 13.8 \\
\hline Total & 1.5 & 3.9 & 7.7 & 5.7 & 11.8 & 1.2 & 3.9 & 0.1 & 35.8 \\
\hline
\end{tabular}

Table 3 shows that during single-sex interactions women resorted to substantially more sequential turn-switching $(6.7 \%)$ than men $(1.6 \%)$, in contrast men resorted to more non-sequential switching $(4.1 \%)$ than women $(2.6 \%)$. In other words, women turn-switched non-sequentially among themselves to a much lesser degree than they turn-switched sequentially, while men resorted to less sequential switching at a turn boundary between one another. It seems that both women and men slightly favored intersentential switches over intrasentential switches when conversing with an interlocutor of the same sex, though the proportional difference in these types of switches between women and men was slim. Men, even though, seemed to favor intersentential switches since they comprised about twice the proportion of intrasentential switches. There were marked differences between women and men in the proportion of single-word switches. Women among themselves utilized approximately $22.3 \%$ single-word switches, whilst men only $7.1 \%$ in their conversations with each other. Women showed greater preference for nouns (14.4\%) and adjectives (6.1\%) than verbs $(1.5 \%)$ and adverbs $(0.3 \%)$. Although men preferred to draw on English nouns (6.0\%) more than any other grammatical category, single-word switches were nonetheless negligible in men's speech compared to their female counterparts. Single-adverbial switches for men while conversing with one another were not identified in the CS corpus.

Table 4 shows that when this group of speakers interacted with an interlocutor of the opposite sex or their speech was directed to the general audience, both sexes resorted to relatively similar proportions of sequential switches, while apparently favoring non-sequential switches more. Non-sequential switches were nearly triple the proportion of sequential switches in women's CS and double the percentage in men's speech during mixed-sex interactions. Again, there appeared to be no substantial differences between the sexes in intersentential and intrasentential CS in mixed sex-interactions, however both sexes slightly favored intersentential CS over intrasentential CS. And women continued to display greater preference for single-word switches more than their male counterparts for all major grammatical categories. Both women $(8.6 \%)$ and men $(3.2 \%)$ favored single nouns in their CS performance. Women still showed greater preference for using single-adjective switches (3.4\%), while men displayed less inclination to use them ( $0.5 \%)$. Both sexes drew less on single-verb switches (women $0.9 \%$ and men $0.3 \%$ ). Although, only one instance of single-adverb switch was identified in the men's corpus of CS during mixed-sex conversations, none were detected for women.

\section{The Sociolinguistic Dimensions of Saudis' CS}

The following are some tentative generalizations regarding the CS data on this group of bilingual Saudi women and men in mixed-sex contexts.

\subsection{Women Overall Code-Switched More than Men.}

Women's verbal behavior showed more preference than men for CS into English. This indicates that not only did 
these female speakers view CS positively, they also perceived use of English to be prestigious. Most probably because the English language enjoys a high level of socio-economic prestige due to its status as a global language and its link with progressive Western educational systems. Primarily for these reasons a growing number of middle-class and affluent Saudis are opting to enroll their offspring within Saudi Arabia in international education programs that provide a curriculum wholly or partially in English. This is evidenced by the increasing number of international schools (Note 2), and private colleges and universities that offer various programs in English. Hence, when these women frequently resorted to English in their Arabic utterances, they may have been possibly invoking a progressive persona and also attempting to elevate their speech. In contrast, male speakers' verbal performance showed overall less CS than females, this finding would suggest that men regarded CS into English less favorably than their female counterparts. For men, it was apparent that Arabic was more often the language of choice in casual conversations. Thus, it would seem that CS into English carries different values for Saudi women and men.

\subsection{Women Resorted to More Single-Noun and Single-Adjective Switches than Men}

Among all single-word switches, nouns represented the highest token count for both women and men in single and mixed-sex conversations. This was probably due to the fact that nouns enjoy relatively less syntactic restrictions (Romaine, 1995, p. 125). Single-adjective switches came next in the frequency counts in this data. It is worth mentioning that Sayahi (2011) found approximately $41 \%$ of all code-switches and borrowings from French by Tunisians were single-noun switches and single-adjective switches were the second largest grammatical category.

There were notable gender differences in single-word switches in the CS data presented here. Women exhibited greater preference for drawing on single-word switches when conversing with one another and during mixed-sex conversations than men. Example 9 is typical of the CS data on women's speech. It highlights how single-word switches were often woven into female speech. The female speaker chose to draw on English words repeatedly while chatting in Arabic, that is, the noun 'nurse' with the prefixed Arabic definite article -al, adjective 'busy',

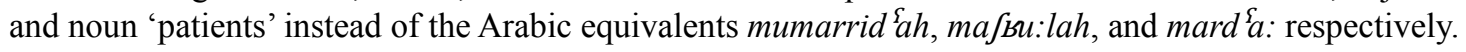

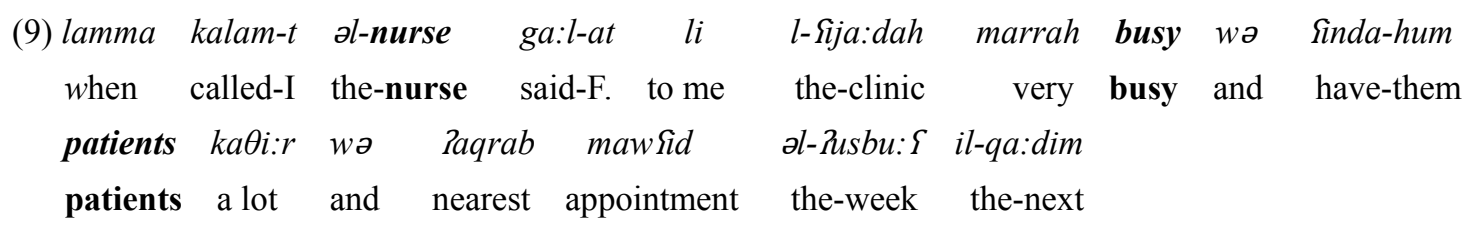

'When I called the nurse she said to me the clinic is very busy and they have a lot of patients and the nearest appointment is next week.'

Women additionally resorted to a higher number of single-word adjective switches than men. Example 10 is typical of single-word adjective switches in women's speech. The example shows the female speaker opting for the English adjectives 'amazing' and 'wow' to display her awe, instead of equivalent Arabic descriptors such as mudhifand ra:RiS respectively. The English forms 'amazing' and 'wow' are highly salient in the ML context, and probably for this reason the adoption of English adjectives into Arabic may provide the speaker with added intensification. Women's partiality for English adjectives also extended to intrasentential switches as example 11 illustrates. One could claim that the woman code-switched to the adjective phrase 'elegant and classy' to give prominence to her friend's qualities and accentuate her admiration for her.

$\begin{array}{cccccccc}\text { (10) Pəl-Sirs } & k a: n & \text { amazing } & \text { wə } & X & k a: n & \text { fakla-ha: wow } \\ \text { the-wedding } & \text { was } & \text { amazing } & \text { and } & X & \text { was } & \text { look-her } & \text { wow }\end{array}$

'The wedding was amazing and $X$ looked wow.'

$\begin{array}{llccccc}\text { (11) } X & \text { dzidan } & \text { elegant and classy } & \text { tihta:r lamma } & \text { təru: } \hbar-i & \text { laha: } & \text { wif } \\ \mathrm{X} & \text { very } & \text { elegant and classy } & \text { bewilders } & \text { when } & \text { goes-you.F } & \text { to her what } \\ \text { tu-sawi } & f i:-k i & & & \\ \text { she-does } & \text { with-you.F. }\end{array}$

' $\mathrm{X}$ very elegant and classy she bewilders you with her hospitality when you go to her.'

Overall, there were much less instances of single-verb switches in the CS corpus, which may partly be due to the difference in word order between Arabic (VSO) and English (SVO). Even though, women resorted to more single-verb switches than men. This finding could be seen as a consequence of women's overall greater 
engagement in CS. Single-adverb switches were scarce in both sexes bilingual discourse, which probably indicates that the integration of English adverbs is more highly constrained by Arabic word order.

7.3 Women's Turn-Switches Were More Inclined towards Linguistic Convergence in Single-Sex Interactions but Showed More Preference for Linguistic Divergence in Mixed-Sex Interactions, Whereas Men's Turn-Switches Overall Exhibited More Linguistic Divergence

As already noted, women's CS at a turn boundary was marked by more linguistic convergence (sequential switching) between one another and more divergence from the language of a speaker of the opposite sex (non-sequential switching), whilst men's CS performance was largely more inclined towards linguistic divergence at a turn boundary. According to Cheshire and Gardner-Chloros (1998), accommodating to the preceding speaker's language by CS at a turn boundary may be considered an index of cooperative linguistic behavior and conversely a change in the bilingual's language from the previous speaker an indicator of uncooperative communication. It is possible then to view women's switch into English at a turn-boundary to accommodate to the language of the previous female speaker/interlocutor as indicative of their more cooperative linguistic style and a display of closeness and friendship with other women as well. Since women resorted to non-sequential turn-switches among themselves to a much lesser degree than sequential switches, this would further indicate that women were more collaborative speakers with each other. On the other hand, during mixed-sex conversations women distinctly displayed more preference for non-sequential switching than sequential turn-switching. Since women showed less inclination to accommodate and switch into English at a turn boundary so that their language corresponded to the male speaker's usage, this may indicate that these women wanted to create social distance and a level of formality between them and a speaker of the opposite sex. In this respects, they seemed to be adhering to Saudi cultural values, which favored social distance between the sexes. Men's CS was characterized by more than double the proportion of non-sequential switching at a turn boundary than sequential switching among each other and in mixed-sex interactions. Men's preference often not to accommodate to the previous speaker's/interlocutor's use of English at a turn boundary maybe viewed as a display of their less cooperative linguistic behavior or a desire to maintain a degree of social distance or formality between themselves and other persons in public space.

\subsection{No Marked Gender Differences in Intersentential and Intrasentential Switching}

It appears that there were no substantial gender differences in intersentential and intrasentential switching for this group of bilingual Saudi speakers in both single and mixed-sex interactions. However, participants seemingly showed a slight partiality in using one sentence in Arabic and another in English (intersentential CS) instead of incorporating English fragments within the ML (intrasentential CS). The rationale behind the small preference for intersentential CS might be that this type of code-switch requires utterances to conform to the grammar of one or the other language. Insertion of EL segments in the morphosyntactic frame of ML (intrasentential CS) would be more structurally constrained. This is a key premise of the MLF Model (Myers-Scotton, p. 1993), that is, there are "key hierarchies" between EL and ML grammars which have the effect of constraining the selection of the output in the production of intrasentential CS utterances. Of interest here also is that men among themselves and with a speaker/ audience of the opposite sex noticeably favored intersentential CS considerably more than intrasentential CS. Other studies have also found men to exhibit a slight tendency to code-switch intersententially, whilst women code-switched intrasententially more (Cheshire \& Gardner-Chloros, 1998; Sayahi, 2011).

\section{Conclusion}

Even though the study examines the bilingual performance of a small group of women and men within a particular context, dinner gatherings, the results offered here can provide insights regarding the interaction of gender and CS performance by Saudi's in mixed-sex and single-sex interactions. Primarily, CS into English would seem to be an emblematic part of Saudi female speech style since women overall resorted to substantially more CS into English than male speakers. Given the socio-economic prestige of English in Saudi Arabia, frequent CS into English maybe perceived by women as producing an elevated style of speech. Men's speech, on the other hand, incorporated less CS into English, which would indicate that the in-group language for men is Arabic. In mixed-sex interactions, both women and men favored not accommodating to the previous speaker/interlocutor switch into English, which would display a degree of social distance and formality between them and the person of the opposite sex. CS performance seems then to be constrained by Saudi culture, which encourages interaction between the sexes to be kept at quite a formal level. It seems that although this group of Saudis challenged cultural norms by socializing in mixed-sex contexts, they still seemed to be adhering to wider community norms that value distance between the sexes and encourage a display of formality between married 
couples in public as well. Apparently, then underpinning CS patterns are lingering cultural customs and gendered sociocultural ideologies of language. An important question for future research is to what extent could possible differences in CS performance be explained by Saudi women's and men's social and ideological positions and how far suggested CS gender patterns identified in this study are characteristic of the broader Saudi context.

\section{References}

Al Batoush, A. M. (2014). English words in colloquial Jordanian Arabic. International Journal of Linguistics, 6(2), 98-108. http://dx.doi.org/10.5296/ijl.v6i2.5086

Alfonzetti, G. (1998). The conversational dimension in code-switching between Italian and dialect in Sicily. In P. Auer (Ed.), Code-switching in conversation: Language, interaction and identity (pp. 180-214). London and New York: Routledge.

Appel, R., \& Muysken, P. (1987). Language contact and bilingualism. London: Edward Arnold.

Atawneh, A. (2007). English loanwords. In K. Versteegh, M. Eid, A. Elgbali, M. Woidich \& A. Zaborski (Eds.), Encyclopedia of Arabic Language and Linguistics (Vol. 1, pp. 29-35). Leiden: Brill.

Auer, P. (Ed.). (1998). Code-switching in conversation: Language, interaction and identity. London and New York: Routledge.

Cheshire, J., \& Gardner-Chloros, P. (1998). Code-switching and the sociolinguistic gender pattern. The International Journal of the Sociology of Language, 129, 5-34. http://dx.doi.org/10.1515/ijsl.1998.129.5

Finnis, K. A. (2014). Variation within a Greek-Cypriot community of practice in London: Code-switching, gender, and identity. Language in Society, 43, 287-310. http://dx.doi.org/10.1017/S0047404514000207

Gardner-Chloros, P. (2009). Code-switching. Cambridge: Cambridge University Press.

Hassanein, A. T. (2009). Youth speech. In K. Versteegh, M. Eid, A. Elgbali, M. Woidich \& A. Zaborski (Eds.), Encyclopedia of Arabic Language and Linguistics (Vol. 4, pp. 764-767). Leiden: Brill.

International School Consultancy Group. (2015). Global Report. Retrieved from $\mathrm{http}: / / \mathrm{www}$.iscresearch.com/information/isc-news.aspx

Kebeya, H. (2013). Inter-intra-sentential switching: Are they really comparable? International Journal of Humanities and Social Science, 3(5), 225-233. Retrieved from http://www.ijhssnet.com/journals/Vol_3_No_5_March_2013/22.pdf

Muysken, P. (2000). Bilingual speech a typology of code-mixing. Cambridge: Cambridge University Press.

Myers-Scotton, C. (1992). Comparing code-switchng and borrowing. Journal of Multilingual and Multicultural Development, 13(1/2), 19-39. http://dx.doi.org/10.1080/01434632.1992.9994481

Myers-Scotton, C. (1993). Dueling languages. Oxford: Oxford University Press.

Myers-Scotton, C. (2002). Contact linguistics: Bilingual encounters and grammatical outcomes. Oxford: Oxford University Press. http://dx.doi.org/10.1093/acprof:oso/9780198299530.001.0001

Poplack, S. (1980). Sometimes I'll start a sentence in Spanish y termino en español. Linguisitcs, 18(7-8), 581-618.

Romaine, S. (1995). Bilingualism (2nd ed.). Oxford, England: Blackwell Publishers Ltd.

Rouchdy, A. (1992). Borrowing in Arab-American speech. In A. Rouchdy (Ed.), The Arabic Language in America (pp. 36-49). Detroit, United States: Wayne State University Press.

Sadiqi, F. (2003). Women, gender, and language in Morocco. Leiden, Netherlands: Brill.

Sayahi, L. (2011). Code-switching and language change in Tunisia. The International Journal of the Sociology of Language, 211, 113-133. http://dx.doi.org/10.1515/ijsl.2011.040

\section{Notes}

Note 1. Original quotes and bracketing are retained.

Note 2. According to the International School Consultancy group, at the beginning of 2015 Saudi Arabia had 203 International schools that provided a curriculum wholly or partially in English. 


\section{Copyrights}

Copyright for this article is retained by the author(s), with first publication rights granted to the journal.

This is an open-access article distributed under the terms and conditions of the Creative Commons Attribution license (http://creativecommons.org/licenses/by/3.0/). 